\title{
Deep-Sea Bottom Fisheries and the Protection of Seabed Ecosystems: Problems, Progress and Prospects
}

\author{
Richard Caddell
}

Of the myriad industrial activities currently undertaken in the marine environment, fisheries have progressively emerged as 'the most widespread source of anthropogenic physical disturbance to global seabed habitats.' ${ }^{1}$ Demersal fisheries (i.e., those targeting benthic and benthopelagic species, whose core habitats comprise the seabed or areas in very close proximity to it) have been conducted for centuries and are of enduring commercial and nutritional importance to many States. However, as with numerous other fishing practices, technological advances have dramatically transformed demersal fisheries over the past half-century. ${ }^{2}$ While seabed fisheries were historically concentrated in coastal and inshore locations, the steady depletion of shallow-water stocks has subsequently forced many fishers to pursue offshore and deep-sea alternatives. ${ }^{3}$ Consequently, the mean depth of global fisheries has expanded four-fold since the mid-196os, ${ }^{4}$ as industrial fleets have increasingly targeted new deep-water opportunities, notably those located within areas beyond national jurisdiction $(\mathrm{ABNJ})$. Although fishing is by no means a new use of the seabed, the poorly regulated proliferation of fisheries into unprecedented depths has nevertheless generated novel environmental and management concerns, with worrying implications for the enduring health and integrity of benthic ecosystems.

1 J.G. Hiddink et al., 'Global Analysis of Depletion and Recovery of Seabed Biota After Bottom Trawling Disturbance' (2017) 114 PNAS 8301, 8301. Even in regions noted for an extensive offshore industrial presence, the impact of fisheries on seabed ecosystems often outweighs that of all other anthropogenic activities combined: A.R. Benn et al., 'Human Activities on the Deep Seafloor in the North East Atlantic: An Assessment of Spatial Extent' (2010) 5 PLoS One e12730.

2 W. Swartz et al., 'The Spatial Expansion and Ecological Footprint of Fisheries (1950 to Present)' (2010) 5 PLoS One e15143.

3 T. Morato et al., 'Fishing Down The Deep' (2006) 7 Fish and Fisheries 24, 31.

4 E.A. Norse et al., 'Sustainability of Deep-Sea Fisheries' (2012) 36 Marine Policy, 307, 308. 
Demersal fisheries deploy an array of gear to catch their respective target species, all of which involve at least some contact with the seabed, thereby posing varying degrees of collateral risk to the benthic environment. ${ }^{5}$ Some equipment - such as traps and pots - ultimately exert a superficial impact upon marine ecosystems. ${ }^{6}$ Others - notably gillnets and longlines - inflict little physical damage to the seabed itself, but have provoked rather different regulatory anxieties due to their propensity for incidental catches of non-target species, particularly marine mammals. ${ }^{7}$ Instead, bottom fisheries ${ }^{8}$ - especially those engaged in bottom trawling, ${ }^{9}$ involving the dragging of weighted nets over the seabed - are by some distance the most ecologically injurious forms of demersal fishing. They also remain among the most prevalent, with approximately $20-25 \%$ of all current global seafood landings attributed to bottom trawling. ${ }^{10}$

The advent of bottom trawling can be traced back to the late fourteenth century, ${ }_{11}^{11}$ although historical objections to its impacts were often confined to overfishing and the displacement of small-scale fishers by industrial fleets. ${ }^{12}$ Nevertheless, even by the 186 os, regular complaints were raised over the 'scouring' of the seabed by trawl nets. ${ }^{13}$ More recent ecological vexations over bottom trawling have concerned the scraping of vulnerable benthic sediments, ${ }^{14}$

M.J. Kaiser et al., 'Prioritization of Knowledge-Needs to Achieve Best Practices for Bottom Trawling in Relation to Seabed Habitats' (2016) 17 Fish and Fisheries 637, 639.

6 F. Stephenson et al., 'Experimental Potting Impacts on Common UK Reef Habitats in Areas of High and Low Fishing Pressure' (2017) 74 ICES Journal of Marine Science 1648, 1657 .

7 A.J. Reid, 'The Looming Crisis: Interactions between Marine Mammals and Fisheries' (2008) 89 Journal of Mammalogy 541, 542-543.

8 Bottom fisheries are defined by the UN Food and Agriculture Organization (FAO) as any fishery that uses gear 'that either contact or are likely to contact the sea floor during the course of the fishing operation': A. Bensch et al., Worldwide Review of Bottom Fisheries in the High Seas (FAO: Rome, 2009), 2.

9 Bottom trawling is an umbrella term for the use of a variety of gear, each of which uses variations that encapsulate weighted features with the capacity to impact both hard- and soft-bottom benthic ecosystems: see further J.W. Valdermansen, T. Jørgensen and A. Engås, Options to Mitigate Bottom Habitat Impact of Dragged Gears (FAO: Rome, 2007), 5-18.

10 Hiddink (n.1), 8301 (extrapolating global catch data collated by the FAo since 2009).

11 C. Roberts, The Unnatural History of the Sea (Island Press: Washington DC, 2007), 131-2.

12 T.K. Kerby, W.W.L. Cheung and G.H. Engelhard, 'The United Kingdom's Role in North Sea Demersal Fisheries: A Hundred Year Perspective' (2012) 22 Reviews in Fish Biology and Fisheries 621, 629.

13 R.H. Thurstan, J.P. Hawkins and C.M. Roberts, 'Origins of the Bottom Trawling Controversy in the British Isles: 19th Century Witness Testimonies Reveal Evidence of Early Fishery Declines' (2014) 15 Fish and Fisheries 506, 515.

14 F.G. O'Neill and A. Ivanović, 'The Physical Impact of Towed Demersal Fishing Gears on Soft Sediments' (2016) 73(Supplement) ICES Journal of Marine Science 5, 12. 
damage to submarine features, ${ }^{15}$ the removal of habitat-forming species ${ }^{16}$ and the disturbance of complex benthic ecosystems which may in turn further compromise fish productivity. ${ }^{17}$ Moreover, while bottom trawling may inflict specific localised impacts upon the seabed, these fisheries also represent a significant contribution to the cumulative footprint of anthropogenic activities in the global oceans, hence their effects may be exacerbated in tandem with those of other industries. ${ }^{18}$ Seabed ecosystems are slow to recover from such impacts: although data are currently limited, full regeneration appears likely to be a multi-decadal process and one fraught with scientific uncertainty. ${ }^{19}$

The prospective impact of bottom trawling is amplified in the case of deep-sea fisheries. In order to facilitate fishing at advanced depths, larger and heavier equipment is required to ensure the effective operation of the trawl, hence these activities are often significantly more destructive to the seabed than trawling undertaken in shallower waters. ${ }^{20}$ Likewise, trawling is often conducted repeatedly and intensively in particular locations, notably in the vicinity of seamounts and other fragile submarine features due to habitual aggregation of fish in many such areas, ${ }^{21}$ thereby representing a serious threat to the integrity of seabed ecosystems. ${ }^{22}$ Such fisheries also pose considerable risks to long-term sustainability of their target species. Indeed, in order to survive at advanced depths, in an environment characterised by cold temperatures, little light and limited productivity, deep-sea fish typically

15 M.R. Clark et al., 'The Impacts of Deep-Sea Fisheries on Benthic Communities: A Review' (2016) 73(Supplement) ICES Journal of Marine Science 51, $5^{2}$.

16 S.F. Thrush, K.E. Ellingsen and K. Davis, 'Implications of Fisheries Impacts to Seabed Biodiversity and Ecosystem-Based Management' (2016) 73(Supplement) ICES Journal of Marine Science 44, 45.

17 J. Collie et al., 'Indirect Effects of Bottom Fishing on the Productivity of Marine Fish' (2017) 18 Fish and Fisheries 619, 634 .

18 Thrush (n.16), 45-46. Nor are benthic ecosystems the only fragile features at risk concerns have also been raised over the impacts of trawling upon underwater cultural heritage: M.L. Brennan et al., 'Quantification of Bottom Trawl Fishing Damage to Ancient Shipwreck Sites' (2016) 371 Marine Geology 82.

19 M.R. Clark et al., 'Little Evidence of Benthic Community Resilience to Bottom Trawling on Seamounts After 15 Years' (2019) 6 Frontiers in Marine Science 1, 13.

$20 \quad$ Clark (n.15), $5^{2}$.

21 Although a definitive accounting remains elusive for all fish species for which seamounts form an essential habitat, current projections indicate that approximately 800 separate species of fish may be considered seamount species, while a considerable array of additional species aggregate around such features at some stage during their life cycles: T. Morato, W.W.L. Cheung and T.J. Pitcher, 'Vulnerability of Seamount Fish to Fishing: Fuzzy Analysis of Life History Attributes' (2006) 68 Journal of Fish Biology 209.

22 A. Pusceddu et al., 'Chronic and Intensive Bottom Trawling Impairs Deep-Sea Biodiversity and Ecosystem Functioning' (2014) 111 PNAS 8861, 8861. 
exhibit delayed sexual maturity, slow growth and a high maximum age, hence stocks may become rapidly depleted with little scope to regenerate swiftly. ${ }^{23}$ Compounding these concerns, catches from deep-sea trawling provide a negligible contribution to current nutritional needs, accounting for less than $0.5 \%$ of global landings, ${ }^{24}$ while causing significant long-term damage to the seabed in the process. Moreover, deep-sea fishing in ABNJ is conducted by relatively few national fleets, thereby inflicting a strikingly disproportionate degree of harm upon the global commons relative to its numerical participants.

Despite these concerns, until the turn of the present century, many bottom fisheries were subject to surprisingly minimal regulation, as regional fisheries management organisations (RFMOs) either lacked an express mandate to address benthic ecosystems or had yet to be established in respect of significant portions of the global oceans, while little provision had been made for seabed fishing within the overarching legal framework provided by the United Nations Convention on the Law of the Sea $1982 .{ }^{25}$ This has since been addressed through the graduated development of a distinct tier of regulation for seabed ecosystems, which has emerged largely ab initio over the course of the past two decades. The contemporary oversight of deep-sea bottom fisheries accordingly represents an intriguing case-study of the development of regulatory standards concerning the seabed. In this regard, regulatory momentum has been primarily channelled through the United Nations General Assembly (UNGA), which has adopted a series of highly influential Resolutions calling for the protection of vulnerable marine ecosystems (VMEs) on the seabed. The political impetus provided by multiple UNGA Resolutions has in turn prompted the adoption of complementary conservation and management measures by RFMOs, flag states and other pertinent actors. As this Chapter will demonstrate, considerable progress has since been made towards the development of uniform standards for bottom fishing, although the implementation of this framework remains far from complete. Such shortcomings will accordingly need to be further addressed in order to operationalise the commitments established under this collective of UNGA Resolutions, and thus to fully protect benthic ecosystems from the adverse impacts of fishing activities.

To this end, this Chapter first outlines the emergence of global standards towards the protection of VMEs, examining the limits of global instruments and tracing the development of the pertinent UNGA commitments (Section 2).

\footnotetext{
23 Norse (n.4), 317.

24 L. Victorero et al., 'Out of Sight, but Within Reach: A Global History of Bottom-Trawled Deep-Sea Fisheries from >400m Depth' (2018) 5 Frontiers in Marine Ecology 1, 4.

251883 UnTS 396 [hereinafter 'LOSC'].
} 
The Chapter then examines the extent to which these commitments have been implemented by RFMOs and other pertinent actors (Section 3), before advancing a series of conclusions as to the future regulatory landscape concerning bottom fisheries (Section 4).

\section{The Legal Framework for the Regulation of Deep-Sea}

\section{Bottom Fisheries}

\subsection{Fisheries, the Seabed and the Limitations of the LosC}

Until the early twenty-first century, deep-sea bottom fisheries were largely overlooked by international law. Even as deep-sea trawling began to expand on an unprecedented scale from the mid-1970s, such practices remained largely inured from regulatory scrutiny as the 'out of sight, out of mind' nature of bottom fishing in remote locations ensured that there was little popular appreciation of its deleterious impacts upon the seabed. Instead, multilateral fisheries regulation continued to focus primarily on the management of staple pelagic stocks, such as salmon or tuna. This is perhaps unsurprising, since deepsea fish have not traditionally constituted an attractive cohort of target species, either physically or economically. However, by the 1980 s a number of deepsea species had undergone something of a gastronomic renaissance. Having initially been taken - and often discarded - as undesirable by-catch, prominent seafood chefs began to appreciate that their versatile flavour and texture allowed for considerable culinary creativity. ${ }^{26}$ This subsequently created an unprecedented demand for particular fish that had rarely been pursued - or regulated - as a target stock. Coupled with the tactical rebranding of many species to render their previous sobriquets rather more palatable to discerning diners - for instance, 'slimehead' and 'toothfish' have been rechristened as 'orange roughy' and 'Chilean seabass' respectively ${ }^{27}$ - distant water deepsea fishing was swiftly transformed into a highly lucrative undertaking. At the same time, however, this unexpectedly elevated demand starkly exposed acute governance gaps in the international framework for the regulation of fisheries and seabed ecosystems. ${ }^{28}$

26 G.B. Knecht, Hooked:A True Story of Pirates, Poaching and the Perfect Fish (Allen \& Unwin: Sydney, 2006), 81-86.

27 For a sobering account of the extent of this practice see J.L. Jacquet and D. Pauly, "Trade Secrets: Renaming and Mislabeling of Seafood' (2008) 32 Marine Policy 309, 311-313.

28 K.M. Gjerde and D. Freestone, 'Unfinished Business: Deep-Sea Fisheries and the Conservation of Marine Biodiversity Beyond National Jurisdiction' (2004) 19 International Journal of Marine and Coastal Law 209, 209. 
A 'perfect storm' of three regulatory lacunae can be seen to have engendered a rapacious frontier mentality towards deep-sea demersal fish. Firstly, RFMOs had yet to be established for substantial geographical portions of the global oceans, meaning that there were few pre-existing governance structures through which such fisheries could be regulated. Secondly, of the comparatively small number of RFM Os that were in existence at the material time, most had been established to regulate a single species and had no express competence over deep-sea stocks. And thirdly, of the four regulators that in principle held a mandate over deep-sea fish, ${ }^{29}$ these powers were seemingly limited to setting stock allocations rather than addressing the wider ecosystem impacts of bottom fisheries. Although (as considered further below) these bodies have tended to interpret their powers proactively in order to advance protective measures for deep-sea ecosystems, arguably only CCAMLR possessed undisputed competence over both the stocks and their surrounding environment. ${ }^{30}$ This effective regulatory vacuum duly facilitated a 'gold rush' among certain fleets, which invested heavily in new technology in order to exploit seabed fisheries resources before meaningful management actions could be elaborated. ${ }^{31}$ Consequently, by the late 199os leading estimates suggested that an area of up to half the size of the global continental shelf was being trawled annually,32 facilitated by a dearth of regulation that ensured that 'people trawl almost anywhere they want, and the sea's equivalents of ancient forests are becoming cattle pastures by default, not by design.' ${ }^{33}$

Little overt guidance towards the responsible pursuit of demersal fisheries was forthcoming from the LOSC. The LOSC elaborates a broad framework for fisheries competences, under which states may utilise fisheries resources on the high seas ${ }^{34}$ and in their respective exclusive economic zones (E EZs),, ${ }^{35}$ subject to obligations concerning the conservation and management of the stocks

29 Namely the North-East Atlantic Fisheries Commission (NEAFC), the Northwest Atlantic Fisheries Organisation (NAFO), the General Fisheries Commission for the Mediterranean (GFCM) and the Commission for the Conservation of Atlantic Marine Living Resources (CCAMLR).

30 E.J. Molenaar, 'Addressing Regulatory Gaps in High Seas Fisheries' (2005) 20 International Journal of Marine and Coastal Law 533, 538.

31 A. Merrie et al., 'An Ocean of Surprises - Trends in Human Use, Unexpected Dynamics and Governance Challenges in Areas beyond National Jurisdiction' (2014) 27 Global Environmental Change 19, 26.

32 L. Wattling and E.A. Norse, 'Disturbance of the Seabed by Mobile Fishing Gear: A Comparison to Forest Clearcutting' (1998) 12 Conservation Biology 1180, 1180.

33 Ibid., 1193.

34 Articles 87(1)(a) and 116.

35 Article 62. 
in question. ${ }^{36}$ Nevertheless, these provisions of the Convention merely establish generalised requirements for the conduct of fisheries: within the EEZ, stocks must be managed in a way that consistently allows for harvest at maximum sustainable yield and that overfishing does not occur as a result, while also taking into consideration the inter-dependence of fish stocks, ${ }^{37}$ with high seas fishing conducted subject to the more ambiguous obligation to exercise 'due regard' towards the interests of others. ${ }^{38}$

Nor were demersal fisheries considered in Part VI of the LOSC, which addresses the continental shelf. Indeed, proposals to specifically regulate benthic and benthopelagic species within the ambit of these provisions - given that they are 'intimately associated with the seabed' - were expressly rejected during the negotiation of the Convention. ${ }^{39}$ Instead, fisheries entitlements on the continental shelf under the LOSC are restricted to the exercise of sovereign rights over sedentary species. ${ }^{40}$ Such species are defined as 'organisms which, at the harvestable stage, either are immobile on or under the seabed or are unable to move except in constant physical contact with the seabed or the subsoil. ${ }^{41}$ This has created sporadic controversy over the status of particular stocks of crustaceans and molluscs, whose biological attributes and behaviour do not always neatly align with the legal understanding of a 'sedentary' species, while also raising questions over the limits of RFMO competences towards certain seabed species. ${ }^{42}$ In any event, the demersal fish targeted by trawling clearly do not meet the Article 77 criteria and thereby lie outside the ambit of Part vi. Such fisheries instead remain subject to the general position

\footnotetext{
$36 \quad$ Articles 61 (EEZ) and 117-119 (high seas).

37 Article 61.

38 Article $87(2)$.

39 S. Borg, Conservation on the High Seas: Harmonizing International Regimes for the Sustainable Use of Marine Resources (Edward Elgar: Cheltenham: 2012) 151.

$40 \quad$ Article $77(1)$.

41 Article 77(4).

42 As recently considered by the Norwegian courts where, in two separate prosecutions against Latvian-flagged crabbing vessels, Norway has sought to enforce its sovereign rights over snow crabs as a lucrative sedentary species: see further I. Dahl and E. Johansen, The NorwegianSnow CrabRegimeandForeign Vessels-ACommentaryontheJurasVilkasDecision of the Øst-Finnmark District Court; available on-line at http://site.uit.no/jclos/2017/03/29/ the-norwegian-snow-crab-regime-and-foreign-vessels-a-commentary-on -the-juras-vilkas-decision-of-the-ost-finnmark-district-court/ and T. Henriksen, The Senator Case - A New Turn in Norway's Dealings with Foreign Vessels Operating in the Waters off Svalbard, available on-line at https://site.uit.no/jclos/2019/02/28/the-senator -case-a-new-turn-in-norways-dealings-with-foreign-vessels-operating-in-the-waters-off -svalbard/.
} 
prescribed in relation to the EEZ, since ' $[\mathrm{t}]$ he rights of the coastal State over the continental shelf do not affect the legal status of the superjacent waters'. ${ }^{43}$

Similarly, the LOSC made no direct provision for the regulation of fishing in those areas of the seabed that lie outside the confines of national jurisdiction (the 'Area'). The provisions of Part XI, which pertain to the Area, clarify that the concept of 'resources' in this context is restricted to minerals. ${ }^{44}$ As with the continental shelf regime, trawl fishing in the Area is thus subject to the provisions governing the high seas. ${ }^{45}$

A more intriguing position arises where the coastal state has exercised its right under Article 76 of the Losc to extend its continental shelf beyond the orthodox 200 nautical mile limit. This may lead to conflicts between the interests of the coastal state in protecting the seabed environment in this area - either for its own intrinsic value or to safeguard a lucrative aggregation of sedentary species - and those of another state intending to undertake bottom trawling by exercising its long-established rights to fish on the high seas, as guaranteed under Article 87(2). A coastal state cannot unilaterally impose a blanket ban on trawling across the entirety of its outer continental shelf, since Article 78(2) specifies that " $[t]$ he exercise of the rights of the coastal State over the continental shelf must not infringe or result in any unjustifiable interference with navigation and other rights and freedoms of other States as provided for in this Convention'. Instead, this raises the possibility that more localised restrictions could represent a justifiable interference with the exercise of high seas freedoms. Indeed, a sense of coexistence between states has long been considered necessary where there are bifurcated entitlements applicable to overlapping areas of maritime jurisdiction: as confirmed by the International Tribunal for the Law of the Sea (ITLOS) in the Bangladesh/Myanmar case, 'the legal regime of the continental shelf has always coexisted with another legal regime in the same area ... each coastal State must exercise its rights and perform its duties with due regard to the rights and duties of the other'.46 By analogy to practice in other industries, Mossop suggests that a coastal state could prospectively introduce limited restrictions on bottom trawling in these

\footnotetext{
43 Article 78(1).

44 Article 133.

45 Article 135.

46 Dispute concerning delimitation of the maritime boundary between Bangladesh and Myanmar in the Bay of Bengal (Bangladesh/Myanmar); Judgment of 14 March 2012: para 475 .
} 
areas, provided that interference with legitimate high seas freedoms is minimal and appropriate consultations have been undertaken. ${ }^{47}$

Nevertheless, given the limited ability of the coastal state to control activities in the superjacent water column of the high seas, such restrictions are likely to be markedly strengthened where they operate in tandem with those of a multilateral body, such as an RFMO or a Regional Seas Organisation (RSO) and are arguably weakened where such collaboration is not forthcoming. For instance, an RSO may implement a marine protected area (M PA) or an RFMO may establish concurrent restrictions on fishing in areas of the high seas that overlay locations of the outer continental shelf for which a coastal state has sought to curtail bottom fisheries. As noted below, given that ABNJ are primarily regulated on a sectoral basis, the optimal solution for seabed locations of particular ecological sensitivity would be for each of these designations to operate in tandem. In a limited number of cases, such designations have been successfully aligned: most notably in the context of the Altair and Antialtair Seamounts located on the outer continental shelf of Portugal, which have been protected from trawling by the Portuguese authorities, with parallel fishing restrictions imposed in the superjacent water column by the pertinent RFMO, NEAFC, alongside an overlapping MPA designation under the Convention for the Protection of the Marine Environment of the North East Atlantic, ${ }^{48}$ which has thus secured the highest possible degree of protection for these features. ${ }^{49}$ This is not the case for all such features purportedly protected by states on their outer continental shelves, however, as other Portuguese designations attest. ${ }^{50}$

This is not to suggest that delicate seabed features are devoid of legal protection under the LOSC. Indeed, benthic ecosystems are more directly regulated under Part XII of the LOSC, addressing the protection and preservation of the marine environment, with Articles 192 and 194 of particular relevance. Both provisions have been subject to extensive judicial consideration in recent years to clarify their application and scope. Article 192 rather concisely provides that ' $\mathrm{s}$ ] tates have the obligation to protect and preserve the marine environment'. In a fisheries context it has been recently acknowledged that Article 192 'extends to the prevention of harms that would affect depleted, threatened, or

\footnotetext{
47 J. Mossop, The Continental Shelf Beyond 200 Nautical Miles: Rights and Responsibilities (Oxford University Press: Oxford, 2016), 195.

482354 UNTS 67 [hereinafter 'OSPAR Convention'].

49 See further Mossop (n.47), 218-220.

5o Ibid., 220.
} 
endangered species indirectly through the destruction of their habitat, ${ }^{\prime}$ which not only provides a basis to protect seabed ecosystems, but also imposes an obligation of due diligence upon flag states to ensure that nationally-registered vessels adhere to relevant conservation and management measures in the conduct of fishing activities. ${ }^{52}$

Similarly, Article 194(5) provides that measures undertaken pursuant to Part XII of the LOSC 'shall include those necessary to protect and preserve rare or fragile ecosystems as well as the habitat of depleted, threatened or endangered species and other forms of marine life'. In the South China Sea Arbitration, it was considered that the general obligation to protect the marine environment advanced in Article 192 is 'given particular shape in the context of fragile ecosystems by Article 194(5) ${ }^{\prime}{ }^{3}$ Although this did not concern bottom fishing per se, the Tribunal nonetheless declared that if a state is deemed to have knowledge that its vessels are conducting destructive fishing activities, a failure to enforce such measures may constitute a breach of the obligation of due diligence. ${ }^{54}$ Like Article 192, recent jurisprudence has clarified that Article 194 is also to be viewed expansively, and is 'not limited to measures aimed strictly at controlling pollution and extends to measures focussed primarily on conservation and the preservation of ecosystems. ${ }^{55}$ As with Article 78(2), when exercising the obligations prescribed under Article 194, states 'shall refrain from unjustifiable interference with activities carried out by other States in the exercise of their rights and in pursuance of their duties in conformity with this Convention, 56 The concept of unjustifiable interference has been recently considered to be 'functionally equivalent' to the obligations to give 'due regard' under Article 56(2) and of good faith under Article 2(3) of the LOsC. ${ }^{57}$ The extent of the obligation under Article 194(4) remains essentially context-dependant, although the Arbitral Panel considered that due regard as applied under Article 56(2) will depend upon the nature of the rights held, their importance, the extent of the anticipated impairment, the nature and importance of the activities and the availability of alternative approaches

\footnotetext{
51 South China Sea Arbitration (Republic of the Philippines v. Peoples' Republic of China), Award of 12 July 2016; para 959. Request for an Advisory Opinion Submitted by the Sub-Regional Fisheries Commission (SRFC); paras 118-140.

53 South China Sea Arbitration (n.51), para 959.

54 Ibid., paras 964-966.

55 Chagos Marine Protected Area Arbitration (Mauritius v. UK), Award of 18 March 2015; para 538 .

56 Article 194(4).

57 Chagos Marine Protected Area Arbitration (n.55), para 540.
} 
and will involve 'at least some consultation'.58 Provided this broad balancing act is undertaken, the possibility for the legitimate interference with fishing rights otherwise guaranteed under the LOSC was pointedly left open in the Chagos Marine Protected Area Arbitration, although this would require 'significant engagement ... to explain the need for the measure and to explore less restrictive alternatives'. Accordingly, Article 194 provides a prospective basis for restricting bottom fishing in areas of known sensitivity, albeit based on meaningful consultations and with the possibility that intended activities may still proceed to a lesser extent in the intended location or be displaced to another area of the seabed.

\subsection{The Evolving UNGA Commitments and the Emergence of the VME Concept}

Notwithstanding the ongoing elaboration of obligations under Part XII of the LOSC, the protection of benthic ecosystems from the damaging impacts of bottom fisheries has been primarily driven by a series of key UNGA Resolutions adopted over the course of the past fifteen years, which have subsequently proved influential in the adoption of unified standards and policies by RFMOs, flag states and other actors. By the late 1990s, concerns began to mount over the proliferation of bottom fisheries and the effective lack of regulation for many demersal species. In some cases, regulation was largely localised and bilateral, as exemplified by the pioneering arrangement between Australia and New Zealand to set allocations for orange roughy in the South Tasman rise. ${ }^{59}$ While such arrangements were predominantly focused on catch limits, allocations and stock analysis, they also introduced localised prohibitions on trawling and demersal fishing in particular locations, albeit that bottom fishing could still proceed with the express authorisation of the parties. ${ }^{60}$ Such initiatives were however few and far between, leading to increased calls for a more globalised tier of regulation over deep-sea bottom fisheries.

$58 \quad$ Ibid., para 518.

59 See further E.J. Molenaar, 'The South Tasman Rise Arrangement and Other Initiatives on Management and Conservation of Orange Roughy' (2001) 16 International Journal of Marine and Coastal Law 77. As Molenaar observes, a series of orange roughy fisheries in the Southern Hemisphere provided a strong test for international fisheries regulation in the interim period between the adoption and entry into force of the UN Fish Stocks Agreement.

6o Arrangement Between the Government of Australia and the Government of New Zealand for the Conservation and Management of Orange Roughy on the South Tasman Rise 2000; reproduced in Molenaar, ibid. 
Despite an emerging degree of support for the improved governance of demersal fisheries, there were strong divergences of opinion over which institution would be best placed to institute effective regulation and whether these activities were best addressed through binding or non-binding means. ${ }^{61}$ In this respect, the UNGA offers particular advantages in providing both a suitably global platform for such discussions, while also avoiding the more loaded issue of whether such standards should be legally binding and thereby trigger substantive consequences if they are not fully implemented. Although UNGA Resolutions are not technically binding, ${ }^{62}$ in recent years they have nevertheless had considerable traction as a regulatory spur to address destructive fishing practices. ${ }^{63}$ This proved to be particularly true in the context of largescale driftnet fishing on the high seas, with a series of UNGA Resolutions in the early 1990s providing a compelling stimulus for specific regulatory activity by RFMOs and other actors, ${ }^{64}$ to the extent to which commentators have suggested that these standards now represent customary international law. ${ }^{65}$

The UNGA driftnet Resolutions provided a helpful regulatory template to promote policies to address the impacts of bottom fishing on seabed ecosystems. In 2002, the UNGA recognised for the first time the need to consider 'the management of risks to marine biodiversity of seamounts and certain other underwater features' ${ }^{66}$ This precipitated a protracted and circular series of discussions within a variety of different multilateral bodies as to the most

61 See D.A. Balton and D.C. Zbicz, 'Managing Deep-Sea Fisheries: Some Threshold Questions' (2004) 19 International Journal of Marine and Coastal Law 247, 252-255.

62 As Harrison observes, UNGA Resolutions are not law-making tools but have had a more nuanced influence on state practice as 'a means of drawing attention to the current threats to fish stocks and encouraging international efforts taking place in other institutions to address them': J. Harrison, Making the Law of the Sea: A Study in the Development of International Law (Cambridge University Press: Cambridge, 2013), 204.

63 See further R. Caddell, 'International Fisheries Law and Interactions with Global Regimes and Processes' in R. Caddell and E.J. Molenaar, Strengthening International Fisheries Law in an Era of Changing Oceans (Hart: Oxford, 2019) 133, 135-137.

64 On the elaboration of these provisions see D.R. Rothwell, "The General Assembly Ban on Driftnet Fishing' in D. Shelton (ed.) Commitment and Compliance: The Role of Non-Binding Norms in the International Legal System (Oxford University Press: Oxford, 2003), 121,126131, W.T. Burke, M. Freeberg and E.L. Miles, 'United Nations Resolutions on Driftnet Fishing: An Unsustainable Precedent for High Seas and Coastal Fisheries Management' (1994) 25 Ocean Development and International Law 127, 137-144 and R. Caddell, 'Caught in the Net: Driftnet Fishing Restrictions and the European Court of Justice' (2010) 22 Journal of Environmental Law 301, 301-304.

65 G.J. Hewison, 'The Legally Binding Nature of the Moratorium on Large-Scale High Seas Driftnet Fishing' (1994) 25 Journal of Maritime Law and Commerce 557, 578-580.

Resolution 57/141 of 12 December 2002, para 56. 
appropriate forum through which bottom fishing concerns might be directed. ${ }^{67}$ Since 2003, the UNGA has amalgamated its previously fragmented pronouncements on fisheries matters into a specific - and often hard-fought - annual Resolution on Sustainable Fisheries. In 2004 the protection of the seabed was addressed for the first time in the UNGA Sustainable Fisheries Resolution. ${ }^{68}$ In four core paragraphs, Resolution 59/25 lamented a general lack of regulatory competence over particular marine ecosystems, calling upon States to apply the precautionary approach to prohibit 'destructive fishing practices, including bottom trawling that has adverse impacts on vulnerable marine ecosystems', until appropriate conservation and management measures have been adopted. ${ }^{69}$

This represents the first - albeit undefined - use of the term 'vulnerable marine ecosystem' which has subsequently become a notable addition to the lexicon of global marine governance. The commitment to seek the interim prohibition of 'destructive fishing practices' on a case-by-case basis nonetheless fell short of the full moratorium on trawl fisheries in ABNJ that had been sought by activists - and had indeed been initially present in earlier drafts of the Resolution. ${ }^{70}$ Resolution 59/25 called upon those RFMOs with competence over bottom fisheries to 'urgently' adopt conservation and management measures in accordance with international law to address destructive fishing practices, those inflicting adverse impacts on vMEs and to ensure compliance with such measures. In particular, R FMOs that lacked these competences were requested to extend their pre-existing mandates to regulate bottom fisheries, ${ }^{71}$ while the international community was urged to cooperate in the creation of new RFMOs for unregulated areas of the global oceans, which would be endowed with these powers $a b$ initio and thereby be able to address deep-sea fishing as an immediate operative priority upon their inception.

In 2006, a further and arguably more influential Resolution was adopted by the UNGA, expressing dissatisfaction with the rate of progress since 2004 and calling for steps to be taken 'immediately' to sustainably manage deep-sea fish

67 See further L.A. Kimball, 'Deep-Sea Fisheries of the High Seas: The Management Impasse' (2004) 19 International Journal of Marine and Coastal Law 259, 263-272.

68 Resolution $59 / 25$ of 17 November 2004.

$69 \quad$ Para 66.

70 Y. Takei, Filling Regulatory Gaps in High Seas Fisheries: Discrete High Seas Fish Stocks, Deep-Sea Fisheries and Vulnerable Marine Ecosystems (Martinus Nijhoff: Leiden/Boston: 2013) 112. The rather vague wording of the Resolution also suggests that, while politically prompted by the excesses of trawl fisheries, its application was not confined to such activities.

71 Para 68. 
stocks and vMEs. ${ }^{72}$ In a notable departure, paragraph 83 of Resolution 61/105 listed for the first time a series of targeted action points for RFMOs to complete, notably an assessment of whether individual bottom fishing activities have significant adverse impacts on VMEs, and to ensure that if so they are managed to prevent such impacts, or not authorized to proceed; to identify VMEs and determine whether bottom fishing activities would cause significant adverse impacts to such ecosystems; to close such areas to bottom fishing and ensure that such activities do not proceed unless conservation and management measures have been established to prevent significant adverse impacts; and to require RFMOs to cease bottom fishing where VMEs are encountered.

Resolution 61/105 therefore represents a more nuanced series of restrictions upon bottom fisheries, whereby such commitments are triggered only where there is a threat of a significant adverse impact (SAI) on VMEs. The onus is therefore placed upon identifying locations within which vMEs are present and in establishing a precautionary requirement for vessels to cease fishing upon encountering such features, or to ensure that these areas are preemptively closed to bottom fishing until it may be established that no such encounters are likely to result. In principle, this allows for the co-existence of fisheries and environmental restrictions in locations that have been identified as susceptible to the adverse impacts of deep-sea bottom fishing if not managed proactively.

However, Resolution 61/105 also raised immediate interpretive difficulties, since the threshold by which a marine ecosystem may be considered 'vulnerable' and an adverse impact deemed 'significant' - and, moreover, the precise circumstances under which an 'encounter' may be considered to have occurred in the first place - was not defined, hence the FAO was called upon to elaborate detailed practical guidance on these issues. ${ }^{73}$ As with previous pronouncements, Resolution 61/105 also recommended the expedited development of interim measures to address locations without operational RFMO coverage. ${ }^{74}$ In a novel departure, Resolution 61/105 also directed specific action points to states in areas for which no competent authority was in existence, with flag states requested to cease the national authorisation of fishing vessels in $\mathrm{ABNJ}$ without a competent RFMO or to unilaterally introduce measures applicable to nationally-registered ships to implement the broad commitments advanced therein. ${ }^{75}$

\footnotetext{
72 UNGA Resolution 61/105 of 8 December 2006, para 80.

73 Para 89.

74 Para 85.

75 Para 86.
} 
In 2008, following an extensive technical consultation process, the FAO adopted an influential set of international Guidelines to frame the practical implementation of the relevant UNGA Resolutions for fisheries exploiting deep-sea species 'in a targeted or incidental manner. ${ }^{76}$ The Guidelines have an express application to the high seas - although states are also encouraged to adopt these approaches where appropriate within their national waters - and are applicable to fisheries for which the total catch includes species that can only sustain low exploitation rates and the fishing gear used in this process is likely to contact the seafloor during the course of fishing operations. ${ }^{77}$ The overarching objectives of the Guidelines are therefore to ensure the long-term and sustainable use of marine living resources in the deep-sea and to prevent significant adverse impacts upon vMEs in the process. ${ }^{78}$ Reinforcing the earlier UNGA commitments, states and RFMOs are also requested to adopt and implement measures consistent with the precautionary and ecosystem approaches to fisheries management to identify areas in which vM Es are known or likely to occur and to take action using the best available information. ${ }^{79}$ Nevertheless, the Guidelines are expressly non-binding in nature, ${ }^{80}$ and their regulatory effect instead is considered to have been promoted through the due diligence obligation incumbent upon flag states. ${ }^{81}$

The Guidelines were swiftly endorsed in turn by the UNGA, which called upon states to act to secure their implementation 'immediately, individually and through regional fisheries management organizations and arrangements.' ${ }^{82}$ Nevertheless it was observed that the operative paragraphs of the previous UNGA Resolutions had 'not been sufficiently implemented in all cases'. ${ }^{83}$ Accordingly, Resolution $64 / 72$ reiterated the action points called for in Resolution 61/105, adding a further commitment to promote the adoption of conservation and management measures to ensure the long-term sustainability of deep-sea stocks and associated species, particularly through setting

76 International Guidelines for the Management of Deep-Sea Fisheries in the High Seas (FAO, Rome: 2008), para 5. For an extensive discussion of the formulation of the Guidelines and their prospective legal effect see L. Korseberg, "The Law-Making Effects of the FAO Deep-Sea Fisheries Guidelines' (2018) 67 International and Comparative Law Quarterly 801.

77 Para 8. The total catch is defined herein as 'everything brought up by the gear', reinforcing the notion that the Guidelines ought to be applied even where deep-sea species are taken incidentally.

78 Para 11.

79 Para 12.

8o Abstract to the Guidelines.

81 Korseberg (n.76), 830.

82 Resolution $64 / 72$ of 4 December 20o9, para 113 .

83 Para 118. 
appropriate levels for fishing effort, capacity and catch limits. ${ }^{84}$ This was reinforced in 2011, wherein the UNGA observed that 'despite the progress made, the urgent actions called for in the relevant paragraphs of resolutions 61/105 and $64 / 72$ have not been fully implemented in all cases'. ${ }^{85}$ In a notable departure to the previous instruments, Resolution 66/68 further called for the strengthening of assessment procedures so as 'to take into account individual, collective and cumulative impacts, and for making the assessments publicly available, recognizing that doing so can support transparency and capacity-building globally'.86

Since 2011, these commitments have been regularly affirmed and endorsed, most notably in 2016, where the UNGA called upon states and RFMOs to use the full set of criteria in the FAO Guidelines to identify VMEs and to assess SAIs, to ensure that impact assessments are reviewed periodically and updated where there is a 'substantial change in the fishery' or where there is relevant new information and that conservation and management measures are based upon best available science, especially with regard to improving the effective implementation of thresholds and move-on rules. ${ }^{87}$

\section{Bottom Fisheries and Benthic Ecosystems: Assessing the Impact of the UNGA VME Commitments}

Thus far, eight bodies have established competence over bottom fishing of deep-sea stocks, each of which has adopted a series of measures for the regulation of these fisheries. These are the North-East Atlantic Fisheries Commission (NEAFC), the Northwest Atlantic Fisheries Organisation (NAFO), the Southeast Atlantic Fisheries Organisation (SEAFo), the Southern Indian Ocean Fisheries Agreement (siofA), the North Pacific Fisheries Commission (NPFC), the General Fisheries Commission for the Mediterranean (GFCM), the South Pacific Regional Fisheries Management Organisation (sprfmo) and the Commission for the Conservation of Atlantic Marine Living Resources (CCAMLR). This cohort is also complemented by the European Union (EU), which has also developed standards for bottom fishing in respect of its Member States fishing in ABNJ.

Despite an expanding degree of regulation for deep-sea bottom fisheries in $\mathrm{ABNJ}$, the work of these bodies rather defies neat comparative analysis. Each

\footnotetext{
84 Para $119(\mathrm{~d})$.

85 Resolution 66/68 of 6 December 2011, para 129.

86 Para 129(a).

87 Resolution 71/123 of 13 February 2017, para 180.
} 
RFMO presides over a unique set of ecological conditions (and thereby differing volumes of VMEs to manage), different fishing industries and varying political, material and financial resources and priorities. Accordingly, the following section examines progress towards three key cumulative requirements of the various UNGA Resolutions, namely the need to identify VMEs and to regulate encounters, the establishment of fishing footprints and the elaboration of area closures, and the rectification of problematic governance gaps in respect of bottom fisheries and sensitive seabed ecosystems.

\subsection{VMEs Designations and Encounter Management}

The primary commitment established across the various UNGA Resolutions is the need to identify VMEs and to institute appropriate precautionary management measures in order to protect such areas from significant adverse impacts of bottom fishing. As noted above, these commitments have been given practical voice through the FAO's Deep-sea Fisheries Guidelines. A primary stage in protecting an individual seabed site is therefore to identify it as 'vulnerable', a notion considered by the Guidelines to be

related to the likelihood that a population, community, or habitat will experience substantial alteration from short-term or chronic disturbance, and the likelihood that it would recover and in what time frame ... The most vulnerable ecosystems are those that are both easily disturbed and very slow to recover, or may never recover. ${ }^{88}$

Accordingly, the Guidelines acknowledge that this is itself a variable concept. Features that are 'physically fragile or inherently rare' may be vulnerable to most impacts, while locations may be more resilient and therefore not necessarily 'vulnerable' in particular contexts. ${ }^{89}$ At the heart of this distinction appears to lie an inherent tension between advocates of blanket preservation, and those states with a vested socio-economic interest in bottom fishing. Indeed, as Korseberg observes, there was a relatively limited attendance at the FAO's Technical Consultation in 2008 at which the Guidelines were adopted, but those states that did attend were prominent fishing nations. ${ }^{90}$ A number of states have also strenuously observed that bottom fishing does not necessarily result in catastrophic benthic damage, especially in largely featureless areas of the global seabed, and (perhaps less convincingly in the ABNJ context) that

\begin{tabular}{ll}
\hline 88 & Para 14. \\
89 & Para 15. \\
90 & Korseberg (n.76), 824.
\end{tabular}


such fisheries continue represent a significant source of global food security. ${ }^{91}$ In this regard, fishing states have largely managed to stave off the threat of blanket closures: the Guidelines expressly provide that the risks to a marine ecosystem are to be measured by its vulnerability, the probability of a threat occurring and the mitigation means applied to the threat'. ${ }^{92}$

The Guidelines also elaborate a series of representative characteristics that should be used as criteria in identifying VMEs, namely the uniqueness or rarity of an area or ecosystem; the functional significance of the habitat; the fragility of the area; the life history traits of component species that would make recovery difficult (as exhibited in many species of deep-sea fish); and the structural complexity of an ecosystem. ${ }^{93}$ Although a further, non-exhaustive, series of examples are listed in an Annex to the Guidelines, the individual geological conditions of each region mean that the ultimate decision as to whether a particular site or ecosystem constitutes a VME is made by the RFMO in question. The practice of RFMOs has thus been to develop extensive individual lists of indicator species and ecosystems in order to assess its unique regulatory priorities.

In this respect, there has been a strong emphasis upon sharing examples of best practice between RFMOs, as mandated both by successive UNGA Resolutions and the Guidelines themselves. ${ }^{94}$ This was initially problematic, leading to complaints that support tools were initially limited ${ }^{95}$ and that there were few opportunities for institutional learning between RFMOs. ${ }^{96}$ With

$91 \quad$ Impacts of fishing on vulnerable marine ecosystems: Actions taken by States and regional fisheries management organizations and arrangements to give effect to paragraphs 66 to 69 of General Assembly resolution 59/25 on sustainable fisheries, regarding the impacts of fishing on vulnerable marine ecosystems. Report of the Secretary-General; UN Document A/61/154, para 59 .

92 Para 16.

93 Para 42.

94 Guidelines, para 29.

95 Actions taken by States and regional fisheries management organizations and arrangements to give effect to paragraphs 83 to 90 of General Assembly resolution 61/105 on sustainable fisheries, including through the 1995 Agreement for the Implementation of the Provisions of the United Nations Convention on the Law of the Sea of 10 December 1982 relating to the Conservation and Management of Straddling Fish Stocks and Highly Migratory Fish Stocks, and related instruments: Report of the Secretary-General; UN Document A/64/305, para 202.

96 Actions taken by States and regional fisheries management organizations and arrangements in response to paragraphs 80 and 83 to 87 of General Assembly resolution 61/105 and paragraphs 113 to 117 and 119 to 127 of General Assembly resolution 64/72 on sustainable fisheries, addressing the impacts of bottom fishing on vulnerable marine ecosystems and the long-term sustainability of deep-sea fish stocks: Report of the Secretary-General; UN Document A/66/307, para 207. 
regard to the former concern, considerable progress has been made by the FAO in developing a distinct VME database, which has consolidated a map of areas that are both restricted and open for fishing, as well as maintaining a central repository of information concerning indicator lists for VMEs by individual RFM Os. ${ }^{97}$ Attempts to improve coordination between the various RFMOs with competences over the deep-sea environment have, however, proved arguably less productive. Notwithstanding some initial optimism that these RFMOs could develop collaborative practices akin to the Kobe process of Cooperation to streamline regulatory and administrative activities on issues of common concern, which has proved to be of significant utility to streamlining the work of tuna RFMOs, ${ }^{98}$ only one such meeting has been convened to date. ${ }^{99}$

Where vMEs have been identified, the Guidelines also outline the circumstances under which a SAI may be deemed to have occurred. Such an encounter involves ecosystem integrity being compromised in a manner that '(i) impairs the ability of affected populations to replace themselves; (ii) degrades the long-term natural productivity of habitats; or (iii) causes, on more than a temporary basis, significant loss of species richness, habitat or community types. Impacts should be evaluated individually, in combination and cumulatively'100 The risk of a significant adverse impact therefore triggers further mitigation strategies, primarily in the form of the 'move-on' rule that requires a vessel to retreat to a particular distance away from the VME in question. To this end, a number of RFMOs have developed encounter protocols, which are predominantly based upon the incidental catch of indicator species above threshold levels. ${ }^{101}$

Nevertheless, concerns have been raised that the thresholds established by a number of RFMOs are contingent upon a certain volume of live by-catch. This, for instance, has been the approach of NAFO, NEAFC and SEAFO, yet it is considered a poor tool to identify an encounter since the equipment used is designed exclusively to catch fish and is therefore not conducive to the effective sampling of benthic areas. ${ }^{102}$ Similarly, given that cold-water reefs (which represent a substantial proportion of current VMEs) habitually comprise a

97 For the most recent consolidated version, see http://www.fao.org/in-action/ vulnerable-marine-ecosystems/vme-indicators/en/.

98 See J. Harrison, 'Key Challenges Relating to the Governance of Regional Fisheries' in R. Caddell and E.J. Molenaar (eds), Strengthening International Fisheries Law in an Era of Changing Oceans (Hart: Oxford, 2019) 79, 99.

99 Record of the Meeting of the Deep-Sea Secretariats Contact Group, June 2016, 4.

$100 \quad$ Para 16.

101 See for example, SEAFO CM 30/5 and CCAMLR CM 22-07.

102 P.J. Auster et al., 'Definition and Detection of Vulnerable Marine Ecosystems on the High Seas: Problems with the “Move-On" Rule' (2011) 68 ICES Journal of Marine Science 254, 258. 
framework of primarily dead coral, significant damage may be legitimately inflicted upon a VME without triggering the 'move-on rule'. ${ }^{103}$ There is also a risk that evidence of an encounter may be lost during the retrieval of a net, hence otherwise responsible fishers may be oblivious to an impact, while a longstanding objection to 'move-on' approaches remains the tacit toleration of a documented degree of environmental harm incumbent in the process.

Ultimately, definitively establishing the existence of a VME or whether a SAI has occurred is a complex task, and one that will be subject to constant revision in the light of on-going data-collection requirements. This is especially true given the very limited baseline knowledge of remote seabed areas. The capacity of parties to RFMOs to constantly monitor such ecosystems - even within the areas in which significant research activities have been conducted, let alone those that are currently unfished and largely unexplored - is highly variable, while assessing whether such areas might be sufficiently resilient to prospectively support a degree of fishing is also an exceptionally difficult undertaking. Consequently, while the Guidelines have provided a pathway through which prospective vMEs may be identified and made subject to avoidance techniques, calls for institutional restraint are prevalent and there remains a vocal constituency of advocates for a moratorium on bottom fishing, especially in ABNJ. ${ }^{104}$

\section{2 $\quad$ Fishing Footprints and Protected Areas}

Once VMEs have been identified and appropriate encounter protocols and mitigation strategies have been advanced by RFMOs, a further commitment established within the multiple UNGA Resolutions is to prevent fishing activities where they may have a SAI upon such sites. In this respect, RFMOs can be seen to have advanced two core strategies towards addressing the impacts of fishing in the areas under their jurisdiction. In the first instance, participants have been required to identify their existing fishing footprints - i.e. those locations in which some fishing activity has previously been conducted - wherein fishing is intended to be focused for the foreseeable future. In this manner, the unfished area is to be largely left alone, unless a participant wishes to expand its footprint by initiating an exploratory fishery. If so, any such endeavours are to be subject to prior approval and conducted under strict controls. The second response is the institution of a more traditional area closure, in which fishing is prohibited in order to protect VMEs.

103 UN Document A/66/307 (n.96), para 46.

104 Norse (n.4), 317. 
Since the adoption of the UNGA Resolutions, RFMOs have engaged in a process of mapping the current extent of fished areas with their jurisdictional purviews. In this manner, one key policy has been to seek to confine fisheries within their current locations, while managing VMEs within these areas through encounter protocols and, if necessary, fisheries closures. Within the residue of these unfished areas, bottom fishing is prima facie constrained, although parties may apply to extend their fishing footprints and establish spatially and temporally restricted exploratory fisheries in these locations. Exploratory fisheries are fundamentally different to commercial fisheries and are primarily characterised by an emphasis on low-effort fishing, stringent observer coverage, extensive data-collection commitments and a requirement that activities may not proceed without the express prior approval of the management body.

The process is exemplified by the practice of NEAFC, which in 2008 adopted anInterimExploratoryBottom FishingProtocol forNew BottomFishing Areas. ${ }^{105}$ Under these arrangements NEAFC, in consultation with the International Council on Exploration of the Sea (ICES), maintains a full itinerary of such areas in an Annex to the Recommendation which establishes a definitive, yet adjustable, list of existing fishing footprints. These footprints can be extended, but any activities conducted therein remain classed as 'exploratory' and subject to prior approval, based on the submission of a Notice of Intent to fish, alongside a harvesting plan, mitigation plan and a 'sufficient system' to record data. ${ }^{106}$ Similar systems have been established by SEAFO, ${ }^{107}$ the NFPC, ${ }^{108}$ SPRFMO, ${ }^{109}$ and, especially, CCAMLR, ${ }^{110}$ on whose pioneering system of exploratory fisheries such procedures have been largely modelled. ${ }^{111}$

A more traditional policy response to the problem of the degradation of particular seabed ecosystems on the part of RFMOs has been the designation of restricted areas for bottom fishing, or the outright prohibition of this equipment. In this respect, significant area closures have been instituted by NEAFC,

105 Recommendation XVI:2008.

106 Articles 6 and 7 of Recommendation 9:2015; see Consolidated Text of all NEAFC Recommendations on Regulating Bottom Fishing, available on-line at www.neafc.org.

$107 \mathrm{CM}_{30 / 15}$.

108 Смм 2016-05: Bottom Fisheries and Protection of Vulnerable Marine Ecosystems in the Northeast Pacific Ocean and смм 2016-06: Bottom Fisheries and Protection of Vulnerable Marine Ecosystems in the North-western Pacific Ocean.

109 CMM 03-2014 (Management of Bottom Fishing in the SPRFMO Convention Area).

110 CM 22-06: Bottom Fishing in the Convention Area.

111 See further R. Caddell, 'Precautionary Management and the Development of Future Fishing Opportunities: The International Regulation of New and Exploratory Fisheries (2018) 33 International Journal of Marine and Coastal Law 199, 212-234. 
NAFO, SEAFO and CCAM LR. ${ }^{12}$ Moreover, the GFCM has established three separate Fisheries Restricted Areas (FRAs) for a more modest volume of territory. Most emphatically, bottom trawling has been prohibited by the GFCM in any area below 1000 metres, ${ }^{113}$ while CCAMLR has banned the use of all commercial bottom trawling in the high seas areas under its purview. ${ }^{114}$ Nevertheless, concerns have been raised that mid-water trawling, where nets are piloted through the water column as opposed to being dragged across the seabed, retains considerable scope to damage fragile submarine features, especially seamounts. One notable regulatory departure in this regard is the approach adopted by SPRFMO, which has defined bottom-trawling as including mid-water trawling on seamounts, given the propensity for contact with seabed features even at this comparatively more elevated depth. ${ }^{115}$ This remains a minority view, however, although similar policies were considered by NAFO in 2015, which failed to find consensus on the issue but instead imposed particular restrictions on the design and deployment of mid-water trawl gear.116

Beyond the closures initiated under the auspices of RFMOs, an intriguing recent development has been the elaboration of a new sub-species of area closure led by the fishing industry itself. Such closures have been most closely associated on an international level within the Southern Indian Ocean, while on a national level, extensive seabed areas have also been closed to dredging and bottom trawling within the EEZ of New Zealand. In the context of the Indian Ocean, SIOFA entered into effect in June 2012, although early meetings failed to engender confidence that this new organisation would be able to address VMEs swiftly and effectively. Despite a strong recognition of the need to implement the UNGA VME commitments, the parties were unable to agree on substantive conservation and management measures to address bottom fisheries and instead came to the bland agreement that individual participants should 'endeavour' to limit deep-sea trawling. ${ }^{117}$ Prior to the inauguration of SIOFA, in 2006 the main deep-sea fishing operators established the Southern

112 For a full inventory, see http://www.fao.org/in-action/vulnerable-marine-ecosystems/ vme-indicators/en/.

$113 \mathrm{REC} 29 / 2005 / 1$.

114 CM 22-05: Restrictions on the use of bottom trawling gear in high-seas areas of the Convention Area. Under this provision, bottom trawling could prospectively be deployed for scientific purposes.

115 Report of the Second Scientific Committee Meeting, at p. 15.

116 D Diz, 'The Seamounts of the Sargasso Sea: Adequately Protected?' (2016) 31(2) International Journal of Marine and Coastal Law 359, 366-67.

117 G. Wright et al., 'Advancing Marine Biodiversity Protection through Regional Fisheries Management: A Review of Bottom Fisheries Closures in Areas Beyond National Jurisdiction' (2015) 61 Marine Policy 134, 144. 
Indian Ocean Deepsea Fishers Association (siodfa) and voluntarily designated eleven individual sites as Benthic Protected Areas, albeit with some criticism that these locations were arguably too deep for a viable commercial fishery. ${ }^{118}$ Additional sites within more orthodox fishing grounds were designated as Benthic Protected Areas in 2013. Although these sites remain voluntary in nature - and as an industry initiative they do not carry the prohibitive value of RFMO authority - they have nevertheless had considerable traction within the region, since the benefits of membership of SIODFA are contingent upon compliance with these measures, while individual states have also made this a formal condition for vessel licensing, ${ }^{119}$ suggesting that commercial incentives can be at least as effective as the traditional command-and-control approach adopted by RFMOs.

Similarly, on a national level, an extensive series of Benthic Protection Areas covering over 1.1 million $\mathrm{km}^{2}$ was designated throughout the EEZ of New Zealand in 2007 in which trawling and dredging is precluded, a measure that was also, to the surprise of many domestic commentators, proposed by the national fishing industry. ${ }^{120}$ In a manner reminiscent of the designation of fishing footprints collated by RFMOs, these sites are currently located in areas in which no fishing activities occur, with their prospective value considered to be in curtailing the future expansion of trawling. This approach has also been adopted in neighbouring Australia, were approximately $58 \%$ of the national EEZ is also closed to bottom trawling - albeit encompassing significant locations in which no trawling occurs. ${ }^{121}$ Nevertheless, in New Zealand the proponents of these measures were not entirely motivated by ecological altruism and the initial proposal came with heavy strings attached, with the Deepwater Group seeking an indefinite moratorium on future fisheries closures in the national EEz. ${ }^{22}$ Eventually, this quid pro quo was restricted to an agreement not to create further marine protected areas until 2013. ${ }^{123}$ Moreover, the sites are confined to the seabed itself, with mid-water trawls permitted in the water

118 Ibid. (noting however that this could be a useful designation if fishing activities seek to move deeper in future years).

119 G. Wright and J. Rochette, 'Regional Management of Areas beyond National Jurisdiction in the Western Indian Ocean: State of Play and Possible Ways Forward' (2017) 32 International Journal of Marine and Coastal Law 765, 777-778.

120 J. Helson et al., 'Private Rights, Public Benefits: Industry-Driven Seabed Protection' (2010) 34 Marine Policy 557, 559-563.

121 T.K. Mazor et al., 'Trawl Exposure and Protection of Seabed Fauna at Large Spatial Scales' (2017) 23 Diversity and Distributions 1280, 1280.

122 Helson (n120), 560.

123 T.D. Eddy, 'On the Need for Meaningful Marine Protected Area (MPA) Standards' (2013) 23 Aquatic Conservation: Marine and Freshwater Ecosystems 481, 482. 
column, although considerable monitoring restrictions were placed upon any fishing activities taking place in these areas. ${ }^{124}$ Critics of this approach have argued that these areas are not true MPAs as they merely restrain specific activities yet leave open the possibility of further industrial activities in superjacent waters. ${ }^{125}$ Indeed, the national authorities have long been accused of using these designations as a means of inflating the volume of national MPA coverage, culminating in a rather contrite declaration in April 2019 that Benthic Protection Areas would no longer be counted within the domestic inventory of MPAs. ${ }^{126}$

A further issue of considerable significance in seeking to ensure that holistic protection is applied to sensitive seabed ecosystems is the extent to which fisheries closures are able to dovetail effectively with the management policies of other sectoral regulators. As noted above, seabed features are best protected where both the bethos and the overlaying water column are subject to complementary conservation measures. One striking example of this approach is the pioneering arrangements between NEAFC and OSPAR, whose respective jurisdictional areas intersect within the north-east Atlantic region. The legal mandate of NEAFC is confined to fisheries management, while OSPAR's competence to address "non-polluting human activities" strictly excludes any consideration of fisheries. ${ }^{127}$ In discharging this mandate, OSPAR has placed considerable emphasis upon establishing a network of MPAs and has a comparatively lengthy history of promoting interactions with other organisations in this capacity. ${ }^{128}$

In 2008, a MOU was concluded between NEAFC and OSPAR ${ }^{129}$ to explore areas of mutual interest and formalise a basis for potential future collaboration, for which the most significant outcome was the adoption in 2014 of a Collective Arrangement on cooperation on MPAs in ABNJ. In 2009, NEAFC had closed a series of areas to bottom fishing that broadly corresponded to the designations within the OSPAR MPA network, notably within the Charlie

\footnotetext{
124 Helson (n.120) 564 .

125 T.D. Eddy, 'One Hundred-Fold Difference between Perceived and Actual Levels of Marine Protection in New Zealand' (2014) 46 Marine Policy 61, 64-66.

126 'Conservationists Win Battle Over Government's "Fishing Whoppers"' https://www .stuff.co.nz/national/politics/111766497/conservationists-win-battle-over-govern ments-fishing-whoppers.

127 Article 4 of Annex v to the ospar Convention, added in 1998.

128 See further E.J. Molenaar and A.G. Oude Elferink, 'Marine Protected Areas in Areas beyond National Jurisdiction: The Pioneering Efforts under the OSPAR Convention' (2009) 5 Utrecht Law Review 5, 16.

129 Reproduced on-line at http://www.ospar.org/about/international-cooperation/memo randa-of-understanding.
} 
Gibbs and Mid-Atlantic Ridge MPAs. The Collaborative Arrangement therefore addresses specific locations of mutual interest within the region, which are outlined in Annex I and are jointly maintained by both organisations. While not exclusively focused on area-based management - promising lines of cooperation have also emerged for marine litter and shark conservation - the Collaborative Arrangement provides a platform for data exchange and updates on amendments to the respective restricted areas, with annual meetings having been convened since 2015 to promote these objectives further.

The OSPAR/NEAFC arrangements illustrate both the opportunities and the complexities facing purported collaborative exchanges of this nature. The Collaborative Arrangement seeks to include other pertinent global and regional actors to minimise potential interference with Annex I areas. ${ }^{130}$ OSPAR and NEAFC have thus encouraged the International Maritime Organisation (IMO) and International Seabed Authority (ISA) - which both have the capacity to advance sectoral management tools - to participate in this process, albeit with little success. As with many synergistic endeavours between multilateral bodies, incompatible meeting schedules have inhibited interactions with the IM0. ${ }^{131}$ More significantly, however, such initiatives have met with internal resistance from IMO participants that are geographically and economically removed from shipping activities in the region opposed to devoting time and resources on matters of more localised concern. ${ }^{132}$ Meanwhile, the ISA has considered its participation to be 'premature' in the absence of a clearly defined project-based role in the region. ${ }^{133}$ Wariness about open-ended collaborative demands has also been expressed internally within the OSPAR Commission, with some participants concerned that cross-sectoral management represents a significant but small aspect of an extensive portfolio of activities that could impede the pursuit of more immediate regulatory priorities. ${ }^{134}$

130 The International Commission for the Conservation of Atlantic Tunas (ICCAT) is also identified as a potential partner, given its application to tuna fisheries in the region. Similarly, OSPAR has developed a rather more concise MOU with the North Atlantic Salmon Conservation Organisation (NASCO), although it is more ambiguous and prescribes few action points.

131 Aide Memoire and Key Actions Resulting from the First Meeting under the Collective Agreement, para 2.7 .

$13^{2}$ Aide Memoire and Key Actions Resulting from the Second Meeting under the Collective Agreement, para 3.6.

133 Ibid.

134 D. Freestone et al., 'Can Existing Institutions Protect Biodiversity in Areas beyond National Jurisdiction? Experiences from Two On-Going Processes' (2014) 49 Marine Policy 167, 173. 


\subsection{Governance Gaps}

A further issue of strong concern within the various UNGA Resolutions has been the need to close the significant governance gaps that were exposed by initial attempts to regulate deep-sea fisheries. As observed above, bottom fisheries have long been deceptively under-regulated on an international basis. Many RFMO apply only to single species, while until relatively recently large swathes of the global oceans were not subject to any management coverage. Moreover, as observed above, those RFMOs that did technically exercise a mandate over deep-sea stocks generally lacked the legal competence to fully protect seabed ecosystems. In this respect, closing gaps in regulatory coverage has been an important, and largely successful, element of the commitments established under the UNGA Resolution.

Since the turn of the current century, a suite of new RFMOs - notably siofA, SEAFO, SPRFMO and the NPFC - have been inaugurated and have expressly established the protection of VMEs as a central tenet of the mandates of their constituent bodies. This is most clearly illustrated by the NPFC, for which the preamble to its constituent treaty expressly references the relevant UNGA Resolutions, while the prevention of significant adverse impacts from fisheries upon VMEs is established as a 'general principle' for this body. ${ }^{135}$ Similarly, consideration of VMEs is established as a specific aspect of the mandate of the scientific fora of SPRFMO. ${ }^{136}$ More significantly, perhaps, the conclusion of these instruments was preceded by a series of interim arrangements focused on the regulation of bottom fishing in these areas.

Allied to this, more longstanding RFMOs have been prepared to interpret their mandates - and, indeed, reformulate their constituent provisions - in a broad manner so as to establish a clear degree of management control over bottom fisheries. This is exemplified by the practice of NEAFC, which closed three deep-sea sites to bottom trawling and fishing with static gear, including gillnets and bottom longlines effective from 2005 onwards. ${ }^{137}$ This was a very far-sighted development at the material time, preceding the seminal UNGA Resolution 59/25 by some months, with NEAFC therefore operating in uncharted waters with no global guidance in place. Moreover, it might be questioned whether stricto sensu NEAFC possessed the requisite regulatory

135 Convention on the Conservation and Management of High Seas Fisheries Resources in the North Pacific Ocean (Seoul, 1 April 2012, in force 19 July 2015); preamble and Article 3(e).

136 Convention on the Conservation and Management of High Seas Fishery Resources in the South Pacific Ocean (Auckland, 14 November 2009, in force 24 August 2012) [2012] ATS 28; Article 11.

137 Recommendation 05-2005: Recommendation for the Protection of Vulnerable Deep-Water Habitats. 
competence to do so, which necessitated a very broad interpretation of the Commission's powers on the part of its constituent Members in approving these closures. ${ }^{138}$

More fundamentally, older structures have undertaken a process of considerable reform in recent years to allow them to more centrally address the environmental issues associated with deep-sea fisheries. In this respect, a series of provisions have been 'retro-fitted' into the NAFO Convention, through extensive textual revisions adopted in 2007 in order to promote an ecosystem approach to fisheries management, which eventually entered into effect on 18 May 2017. ${ }^{139}$ Notwithstanding the recent formalisation of these arrangements, many of these obligations had been applied provisionally throughout this interim period, ${ }^{140}$ which enabled NAFO to adopt a series of measures to promote the protection of VMEs. A similar approach has been adopted by the International Commission on the Conservation of Atlantic Tunas (ICCAT), again largely motivated to advance additional protection for VMEs as promoted through the relevant UNGA commitments. ${ }^{141}$

A further important factor has been the role of flag states, which had also been requested to take action to ensure that their vessels fish in a manner that is sympathetic to the benthic environment. In this respect, particular states and entities have been prepared to adopt unilateral standards where their vessels operate in areas lacking RFMO coverage. A particular example is the South-West Atlantic, whereby political complications have precluded the likely establishment of a RFMO for these waters for the foreseeable future. A volume of deep-sea fishing has been conducted in the region, predominantly by Spain, for which a series of voluntary closures have been instituted. More broadly, in 2008, in seeking to implement the pertinent UNGA Resolutions, the EU adopted a Regulation specifically addressing the actions of its Member States in ABNJ for which no RFMO has been established or interim measures have not yet been agreed for the protection of VMEs. ${ }^{142}$ Under this provision, such

\footnotetext{
138 Molenaar (n.3o), 538-39.

139 Convention on Cooperation in the Northwest Atlantic fisheries (Ottawa, 24 October 1978, in force 1 January 1979) 1135 UNTS 369 (Article I(h)). The consolidated version of this instrument, incorporating the 2017 amendments, is available on-line at https://www.nafo .int/Portals/o/PDFs/key-publications/NAFOConvention-2017.pdf.

140 Resolution $1 / 08$ of 26 September 2008 on the Interpretation and Implementation of the Convention on Future Multilateral Cooperation in the Northwest Atlantic Fisheries.

141 See further Z. Scanlon, 'The Art of "Not Undermining": Possibilities within Existing Architecture to Improve Environmental Protections in Areas beyond National Jurisdiction' (2018) 75 ICES Journal of Marine Science 405-416, 410.

142 Council Regulation (EC) No 735/2008 of 15 July 2008 on the protection of vulnerable marine ecosystems in the high seas from the adverse impacts of bottom fishing gears [2008] Official Journal L201/8.
} 
activities may only be conducted pursuant to a special permit ${ }^{143}$ and the use of bottom gear is prohibited in areas 'where no proper scientific assessment has been carried out and made available.'144 A permit may only be issued upon submission of a detailed fishing plan involving an assessment of the potential impacts of fishing in the area, ${ }^{145}$ for which any breach is considered a 'serious infringement' of the Common Fisheries Policy. ${ }^{146}$ In response, Spain has thus far closed nine separate areas to deep-sea bottom fishing by its vessels. In 2017, a further Regulation entered into force banning deep-sea fishing by EU vessels in the North-east Atlantic at depths of 800 metres, ${ }^{147}$ although the unilateral policies introduced by the $\mathrm{EU}$ for this region has generated some disquiet that such measures might exercise an undue influence over the future trajectory of the regulation of VMEs within NEAFC. ${ }^{148}$

\section{$4 \quad$ Conclusions}

While little appreciated in the popular perception of risks to the benthic environment, bottom fisheries have quietly emerged as the most pressing current threat to seabed ecosystems. Although trawl fisheries have constituted a source of regulatory discontent for over six hundred years, meaningful standards to address the increasingly insidious impacts of such activities on the global seabed have only systematically emerged over the course of the present century. Bottom fisheries have proved to be an ecologically expensive food source, inflicting damage with a multi-decadal recovery timescale, while also decimating stocks of deep-sea fish that have often proved manifestly ill-suited to the scale and impact of commercial fishing. Such activities have also, for the most part, been conducted in an effective regulatory vacuum, with deep-sea fisheries representing not only a particularly striking example of the 'tragedy

143 Article 1(1).

144 Article 6(1).

145 Article 3.

146 Article 10.

147 Regulation (EU) No. 2016/2336 of the European Parliament and of the Council of 14 December 2016 establishing specific conditions for fishing for deep-sea stocks in the north-east Atlantic and provisions for fishing in international waters of the north-east Atlantic and repealing Council Regulation (EC) No. 2347/2002 [2016] Official Journal 354/1; On the development of this provision see further G.A. Oanta, 'The European Union's Reform of Deep-Sea Fisheries in the North East Atlantic' (2017) 32 International Journal of Marine and Coastal Law 589 .

148 G.A. Oanta, 'International Organisations and Deep-Sea Fisheries: Current Status and Future Prospects' (2018) 87 Marine Policy 51, 57. 
of the commons', but also serving as a stark metaphor for the failure of international legal frameworks to respond effectively to the challenges of depleted fisheries and damaged oceanic ecosystems. ${ }^{149}$

The response to the challenges presented by deep-sea bottom fishing represents an intriguing case study of the development of regulatory standards for the seabed. In this respect, conservation and management policies have been largely driven through the UNGA, which has in turn designated RFMOs as the primary vehicles through which this problem is to be addressed. Consequently, since 2004 a growing suite of commitments has quietly emerged, which have been implemented by a variety of actors over the past decade. To this end, a series of positive outcomes have been achieved. Governance gaps have been noticeably closed, with new RFMOs having emerged in recent years, many of which feature a specific and unprecedented commitment towards protecting VMEs. Other structures have used the regulatory impetus provided by the UNGA to undertake significant reforms, placing ecosystem considerations more centrally within their revised mandates. Where regulatory lacunae persist, flag states have demonstrated a willingness to step into the breach and promote standards that are rapidly becoming recognised as universal examples of best practice towards threatened seabed environments.

Nevertheless, particular challenges remain and, despite this laudable progress, the commitments elaborated by the relevant UNGA Resolutions have still not been fully realised. Notwithstanding the value of the FAO Guidelines, bottom fisheries may still legitimately wreak considerable damage to the seabed before environmental obligations are engaged. The relevant instruments remain replete with opaque trigger-points for action, the identification of VMEs on a global basis is very much a work in progress and the 'move-on' rule remains a blunt instrument for addressing seabed conservation. Meanwhile the knowledge base concerning seabed ecology - both within, but especially outside - current areas of fishing activity remains extremely patchy. Considerable efforts have been made to elaborate area-based management tools, although a strong emphasis has been placed on developing closures in locations in which fishing does not occur and is unlikely to advance for many years. Regulatory innovations have emerged, particularly those led by industry, although in key instances a primary motivation has been to stave off stronger protective standards. Similarly, despite some notable successes in the North Atlantic region, it has proved difficult to align area-based management

149 K.M. Gjerde, 'High Seas Fisheries Management under the Convention on the Law of the Sea' in D. Freestone, R. Barnes and D. Ong (eds), The Law of the Sea:Progress and Prospects (Oxford University Press: Oxford, 2006) 281, 295. 
tools so as to provide holistic protection to the seabed from multiple sources of anthropogenic activity. With the prevailing legal framework having pointedly bifurcated the regulation of the seabed and that of the water column, the experience of deep-sea bottom fisheries reinforces the need for joined-up management of benthic locations and the superjacent water column in a manner that has proceeded to a regrettably limited degree to date. 